\title{
COMPARTIMENTAÇÃO HIDROGEOLÓGICA DA FORMAÇÃO CAPIRU NA REGIÃo NORTE DE CURITIBA-PR, BRASIL
}

\author{
Ernani Francisco da Rosa Filho ${ }^{1}$, Marcos Justino Guarda²
}

\begin{abstract}
RESUMO O número de habitantes da Região Metropolitana de Curitiba (RMC) aumentou tanto nas últimas décadas sem que tenha havido uma oferta d'água suficiente para atender a demanda total da população. Já existe um deficit e este tende a aumentar no decorrer dos próximos anos. Uma das formas de minimizar este problema, num espaço de tempo relativamente curto e com baixos investimentos, é através da perfuração de poços tubulares nas rochas carstificadas da Formação Capiru, numa faixa de direção NW-SW que está localizada ao norte da cidade de Curitiba. Esta formação geológica na qual está inserida o Aqǘfero cárstico de Curitiba, é composta por metadolomitos (carstificados), por filitos e quartzitos e, secundariamente, por filitos grafitosos, metassiltitos e metamargas. Estas rochas são cortadas por um conjunto de diques básicos, principalmente constituídos por diabásios, os quais são derivados das atividades tectono-magmáticas registradas no Mesozóico e cujas espessuras variam de metros a quilômetros (ver fig. 1). A energia potencial do relevo é caracterizada por um desnível médio de $80 \mathrm{~m}$, atingindo um máximo $200 \mathrm{~m}$, nas proximidades dos vales mais entalhados. O contexto morfoestrutural revela uma compartimentação onde se verificam massas carbonáticas (rochas carbonáticas calcíticas e dolomíticas) com excelentes condições de porosidade e permeabilidade, limitadas por fronteiras praticamente impermeáveis (cristas de filitos e quartzitos entrecortadas por diques de diabásio), com padrão geométrico tipicamente losangular. A dissolução físico-química ocorre preferencialmente no contato das rochas carbonáticas com os solos que o recobrem e, dentro do maciço rochoso, através de suas fraturas. A extração da água por meio de bombeamento de poços, principalmente quando concentrados numa área restrita, favorece os fenômenos de subsidência do terreno. Neste trabalho estão delimitados os seguintes Sub-compartimentos hidrogeológicos, a saber: Colombo, Almirante Tamandaré, Várzea do Capivari e Cabeceira. No Sub-compartimento Colombo foram cadastradas 14 surgências naturais e existem 14 poços tubulares, cuja vazão média corresponde a $100 \mathrm{~m}^{3} / \mathrm{h}$ e as alturas potenciométricas variam entre 927 e $990 \mathrm{~m}$ de altitude. O volume armazenado em sub-superfície na área do rio Capivari e do rio Tumiri é de aproximadamente $14,92 \times 10^{6} \mathrm{~m}^{3} / \mathrm{km}^{2}$ e de $14,92 \times 10^{6} \mathrm{~m}^{3} / \mathrm{km}^{2}$ respectivamente. No perímetro urbano de Colombo é extraído atualmente em torno de $655 \mathrm{~m}^{3} / \mathrm{h}$. No Sub-compartimento Álmirante Tamandaré, existem 12 poços tubulares com uma vazão média igual a $180 \mathrm{~m}^{3} / \mathrm{h}$, sendo que as entradas d'água produtoras distribuem-se entre 40 e $148 \mathrm{~m}$ de profundidade e as cotas potenciométricas distribuem-se entre 938 e $940 \mathrm{~m}$ de altitude. Existem apenas três nascentes cadastradas neste sub-compartimento. Na sede municipal, são operados atualmente quatro poços a uma vazão total de $430 \mathrm{~m}^{3} / \mathrm{h}$. No Subcompartimento Várzea do Capivari, existem seis unidades hidrogeológicas menores, limitadas por cinco diques de diabásio. Os poços, em número de dois, apresentam vazões de até $120 \mathrm{~m} / \mathrm{h}$, as entradas d'água estão mais próximas da superfície e a cota potenciométrica mais elevada está restrita a $890 \mathrm{~m}$ de altitude. No Sub-compartimento Cabeceira estão cadastrados cinco poços tubulares, os quais se distribuem em três unidades morfoestruturais distintas, delimitados por nove diques de diabásio. Existe um poço improdutivo (seco) e o poço de maior vazão produz $204 \mathrm{~m} / \mathrm{h}$, sendo que a cota potenciométrica mais elevada está situada a $1031 \mathrm{~m}$ de altitude. Em termos de conclusão, pressupõe-se que as águas excedentes (nos períodos mais chuvosos) podem ser injetadas no subsolo como forma de recarga artificial; a área a ser escolhida para esta finalidade deverá levar em conta aspectos como qualidade e quantidade da água da fonte de recarga, a distância entre a fonte e o ponto de recarga, a infraestrutura existente, os condicionantes ambientais, o uso e a ocupação do solo e os aspectos legais, especialmente relativos ao uso do solo.
\end{abstract}

Palavras-chave:

Keywords:

\section{INTRODUÇÃO}

A cidade de Curitiba e sua região metropolitana (RMC) apresentaram a maior taxa de crescimento de todas as capitais brasileiras nas duas últimas décadas, não tendo ocorrido, no entanto, um incremento compatível no que se refere à produção de água para o abastecimento público. Tal condicionamento aponta para uma situação de deficit no abastecimento da população que se encontra nesta região, a curto e médio prazo. A captação de águas subterrâneas armazenadas no aqüífero cárstico representa uma alternativa que pode minimizar este problema.

Destaque-se que o sistema de captação na bacia do rio Iguaçu, o qual abastece quase a totalidade da atual população, mostra fortes indícios de exaustão no que se refere à produção de água para abastecimento em conseqüência da densidade populacional (com $87 \%$ da população da RMC que é de 1.900.000 de habitantes).

\footnotetext{
${ }^{I}$ UFPR/DEGEOL/LPH - Centro Politécnico; Curitiba -PR, Brasil (Ernani@ufpr.br)

${ }^{2}$ Mestrando do curso de Geologia da UFPR (marcosjg@sanepar.com.br)
} 
Por outro lado, na bacia hidrográfica do Ribeira, a ocupação populacional é ainda de apenas 13 $\%$; é nesta bacia que ocorre o aqǘf́ero cárstico e, portanto, torna-se emergente a aplicação de medidas que imponha o controle para a ocupação da região objetivando a preservação deste manancial. Atualmente são explotados em torno de $1,0 \mathrm{~m}^{3} / \mathrm{s}$ do aqüífero cárstico, o que permite abastecer os municípios de Almirante Tamandaré, Bocaiúva do Sul, Campo Largo, Campo Magro, Colombo, Itaperuçu e Rio Branco do Sul.

\section{GEOLOGIA}

Os trabalhos referentes à geologia das unidades do Pré-cambriano paranaense, especialmente o Grupo Açungui, iniciaram-se na segunda metade do século passado. Os enfoques dados, de um modo geral, foram essencialmente de caráter estratigráfico e petrográfico. Estudos relativos à exploração e a explotação de metacalcários, bem como de incentivo a estas, no transcorrer do tempo, não foram significativos, excetuando-se o trabalho recente realizado pela CPRM (1998). O mapa geológico da região estudada é apresentado na figura 1.

Saliente-se que a ênfase em termos geológicos é dada a Formação Capiru, em especial à unidade litológica metacarbonática utilizada na exploração de bens minerais e na captação de águas subterrâneas.

Em ordem cronológica, são apresentados alguns dos trabalhos realizados no Grupo Açungui, no qual está inserida a Formação Capiru, que foram utilizados para a elaboração deste artigo, os quais sejam: Maack (1947), Almeida (1956), Bigarella \& Salamuni e Salamuni, 1956, 1958, a,b), Marini \& Bigarella (1967), Marini (1970), Fuck et al. (1971), Fairchild (1977, 1982), Soares (1987), Fassbinder (1996) e da CPRM (1998). A Formação Capiru aflora na porção sudeste do Grupo Açungui e é composta, predominantemente, por metadolomitos, filitos e quartzitos e, secundariamente, por filitos grafitosos, metassiltitos e metamargas. Os quartzitos apresentam-se em camadas métricas com gradações para filitos e às vezes para filitos carbonosos. Podem formar lentes intercaladas nos pacotes de metadolomitos e de filitos. As rochas metacarbonáticas ocorrem em espessos corpos lenticulares e são geralmente maciças, às vezes silicosas. Estas rochas são cortadas por um conjunto de diques básicos, derivados das atividades tectono-magmáticas registradas no Mesozóico. Esses diques ocorrem concentram-se principalmente no eixo do Arco de Ponta Grossa. Apresentam superfícies com áreas de extensões variáveis, na ordem de metros e espessuras que variam de metros a quilômetros, em profundidades. Geralmente apresentam granulometria média e mais raramente, grosseira. São descritos diabásios, diorito, diorito pórfiro e quartzo-diorito. Quando muito alterados, podem ser distinguidos das encaixantes pela sua típica forma esferoidal.

\section{GEOMORFOLOGIA}

A geomorfologia de regiões cársticas apresenta características distintas devido à ação do fenômeno de dissolução sobre as rochas carbonáticas. Esse fenômeno produz um rebaixamento preferencial de certas porções do terreno, nas quais são encontradas feições típicas, como dolinas. $\mathrm{Na}$ área de estudo observa-se um relevo enérgico, onde dominam os cabeços de estratos e espigões, separados por pequenas planícies e vales alongados, com desenvolvimento preferencial segundo a direção NE- SW .

A energia potencial de relevo é caracterizada por um desnível médio de $80 \mathrm{~m}$, atingindo um máximo $200 \mathrm{~m}$, nas proximidades dos vales mais entalhados. O relevo positivo de cabeços de estratos e espigões, é predominantemente originados por quartzitos e filitos intercalados, enquanto as pequenas planícies deprimidas e vales alongados correspondem a áreas com predominância de rochas carbonáticas.

Os diques de diabásio apresentam comportamento diferenciado em relação às encaixantes. Ocorrem como vales quando seccionam cristas de filitos e quartzitos, havendo, no entanto, inversão para cristas alongadas na direção NW-SE, em seu desenvolvimento sobre as rochas carbonáticas.

O contexto morfoestrutural revela uma compartimentação onde se verificam massas carbonáticas (rochas carbonáticas calcíticas e dolomíticas) com excelentes condições de porosidade e permeabilidade, limitadas por fronteiras praticamente impermeáveis (cristas de filito e quartzitos entrecortadas por diques de diabásio), com padrão geométrico tipicamente losangular. 


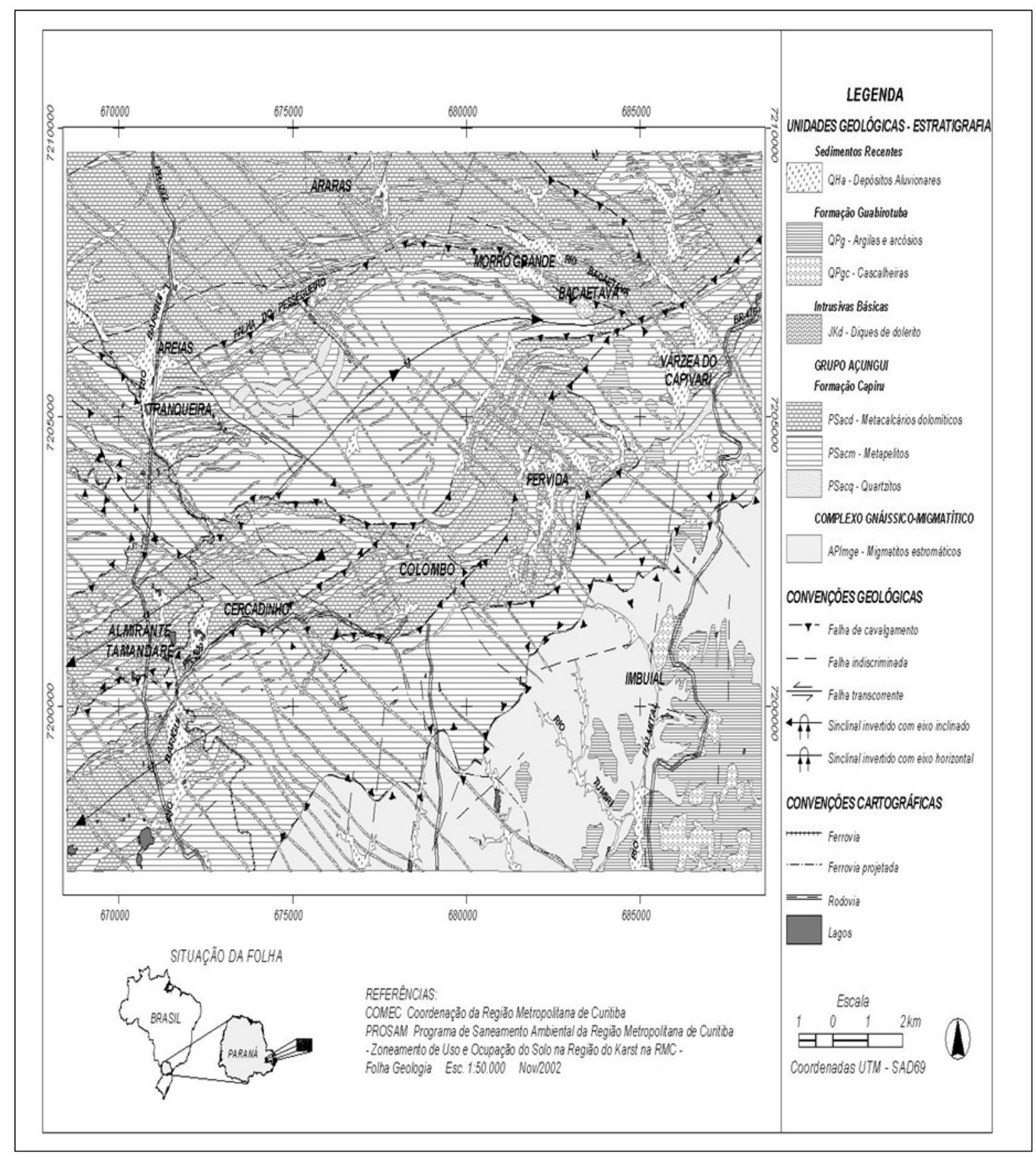

- Mapa geológico da região (Fonte: SANEPAR, 2003).

\section{COMPARTIMENTAÇÃO HIDROGEOLÓGIA DO AQÜÍFERO CÁRSTICO}

\section{Considerações gerais}

Nas rochas carbonáticas carstificadas, a circulação de água subterrânea tem sido alvo de extensivos estudos, por diversos centros de pesquisas mundiais, devido a grande potencialidade em termos de capacidade de armazenamento, bem como porque os fluxos subterrâneos apresentam padrões muito complexos (heterogeneidade e anisotropia). O processo de carstificação das rochas carbonatadas tem origem nos fenômenos de dissolução química, às vezes químicas e físicas, resultando em cavidades variáveis em seu meio. A dissolução é comandada por águas provindas da superfície de caráter necessariamente ácida (ácido carbônico, ácidos da decomposição da matéria orgânica: húmicos, tânicos, fúlvicos, etc.). A dissolução se dá junto ao contato das rochas carbonáticas com os solos (incluindo seus resíduos insolúveis, outras rochas alteradas e mesmo sedimentos) que o recobrem e, dentro do maciço rochoso, através de suas fraturas. Portanto, quanto 
mais fraturada a rocha e quanto mais intensa for a circulação da água, o processo físico-químico da dissolução é mais intenso. I $\quad$ g u a $1 \mathrm{~m}$ e $\mathrm{n} \mathrm{t}$ e complexo e de difícil compreensão em terrenos carstificados, são os fenômenos associados à subsidência do terreno; estes geralmente ocorrem em conseqüência da acomodação do solo, o qual se desloca gradualmente em direção aos espaços abertos no maciço carbonático, Quando se realiza a extração de água de forma aleatória nos aqüíferos cársticos, a subsidência, sucedida de solapamento, é quase sempre acelerada.

Um método sistêmico conduzido sob a ótica de monitoramento de informações hidrológicas, superficiais e subterrâneas, é propício ao entendimento desta problemática porque consideram as entradas e as saídas do conjunto e isto permite a qualificação e a quantificação das variáveis envolvidas. Esta forma de estudo é especialmente importante na medida em que se pode avaliar os limites do sistema e se capacitar a realizar previsões no tocante a eventual evolução da instabilidade de terrenos que poderão gerar subsidência acelerada. Esta forma de estudo exige o monitoramento de informações sobre a distribuição das águas na natureza, a exemplo da distribuição e freqüência da precipitação e da evapotranspiração, bem como da capacidade de campo útil do solo e do volume e distribuição da água que se infiltra de forma difusa através do manto de alteração, em sumidouros e em áreas de descarga direta como as que surgem na superfície como fontes naturais. A obtenção deste tipo de dado, juntamente com o monitoramento sobre o comportamento do nível potenciométrico do aqüífero e das descargas cedidas e/ou extraídas do reservatório subterrâneo, sejam naturais ou através do bombeamento de poços tubulares, são imprescindíveis para a determinação do balanço hídrico.

Dentre os parâmetros envolvidos para o conhecimento de aqüíferos cársticos, alguns possuem dificuldades particulares para serem obtidos e outros são menos problemáticos, exigindo, de qualquer forma, observações e medições diretas. Os parâmetros de avaliação mais incertos são aqueles relacionados com o comportamento hidráulico do fluxo neste tipo de meio, assim como da malha e aberturas através das quais a água escoa, da capacidade de liberação da água e da velocidade de escoamento em seu meio. A maioria dos resultados de medições reflete características pontuais e, portanto, não sendo assim considerados sempre acrescenta percentual de erros muito elevados ao se proceder a extrapolação neste tipo de terreno.

$\mathrm{Na}$ área do aqüífero cárstico, da região de Curitiba, o número de dados computados e o grau de conhecimento dos processos envolvidos ainda são incipientes. Isto ocorre em função da diversidade dos elementos envolvidos, da complexidade de funcionamento do sistema hídrico, do curto espaço de tempo em que se iniciou a coleta de dados relacionados com a explotação do aqǘf́fero e do volume de extração de água que se deseja realizar sobre as áreas de interesse. Com esses dados, de qualquer forma, foi possível definir, mesmo que em nível de proposta inicial, as compartimentações hidrogeológicas descritas a seguir.

É importante destacar que a delimitação dos Sub-compartimentos hidrogeológicos do Aqüífero Cárstico de Curitiba, os quais são apresentados a seguir, foi elaborada sob a coordenação de Álvaro Amoretti Lisboa, no ano de 1992 (SUDERHSA, 1999). Os referidos Sub-compartimentos, podem ser visualizados na figura 1 .

\section{Sub-compartimentos hidrogeológicos}

Cada Sub-compartimento foi delimitado em funçãodas feições geológicas egeomorfológicas que são típicas do desenvolvimento de processos de carstificação na região onde ocorrem as rochas carstificadas da Formação Capiru. Os Subcompartimentos são caracterizados por uma série de unidades morfoestruturais e essas unidades concentram afloramentos de rochas como os metadolomitos e os metadolomitos calcíticos, sendo todas delimitadas pela ocorrência de filitos, quartzitos. As rochas metassedimentares encontram-se cortadas por intrusões de diques de diabásios.

\section{Colombo}

Neste Sub-compartimento, o processo de carstificação apresenta-se bastante avançado e em algumas porções do terreno, verifica-se a superposição de estruturas doliniformes, cujas áreas de coalescência vêm apresentando processos de abatimento diferenciado. Este fenômeno pode ser comprovado pela observação dos caules das árvores que se encontram inclinados em direção ao eixo dos vales, o que retrata a subsidência em andamento. O processo de dissolução também evoluiu nas localidades de Fervida, São João e Capivari, produzindo cavidades de dissolução, com aberturas em torno de 1 a $5 \mathrm{~m}$. 
Tabela 1 - Relação de alguns poços tubulares cadastrados e georeferenciados no Sub-compartimento Colombo.

\begin{tabular}{|c|c|c|c|c|c|c|}
\hline $\begin{array}{c}\text { UTM-W } \\
\text { (m) }\end{array}$ & $\begin{array}{c}\text { UTM-S } \\
\text { (m) }\end{array}$ & Altitude (m) & N. Poten. (m) & $\mathbf{Q}\left(\mathbf{m}^{3} / \mathbf{h}\right)$ & $\mathbf{Q} / \mathbf{s p}\left(\mathbf{m}^{3} / \mathbf{h} / \mathbf{m}\right)$ & E.A. (m) \\
\hline 679780 & 7202980 & 994 & 990,81 & 150,00 & 16,61 & 59 \\
\hline 682640 & 7204200 & 940 & 938,87 & 37,71 & 1,16 & $30 ; 102$ \\
\hline 679740 & 7202470 & 990 & 985,05 & 120,43 & 13,58 & $25-27 ; 95$ \\
\hline 678430 & 7202870 & 958 & 953,31 & 93,91 & 16,05 & $34-40$ \\
\hline 681950 & 7204190 & 932 & 927,58 & 59,39 & 16,32 & 28 \\
\hline 683360 & 7204200 & 938 & 933,68 & 81,63 & 41,02 & $36,5-40$ \\
\hline 679350 & 7202680 & 963 & 961,50 & 85,00 & 1,77 & $38-132$ \\
\hline 679140 & 7202940 & 990 & 962,30 & 98,93 & 8,04 & $43,4-46,4$ \\
\hline 679330 & 7202880 & 985 & 982,84 & 150,00 & 12,85 & $22-26$ \\
\hline
\end{tabular}

Tabela 2 - Relação de alguns poços tubulares cadastrados e georeferenciados Sub-compartimento Colombo.

\begin{tabular}{|c|c|c|c|c|c|c|}
\hline $\begin{array}{c}\text { UTM-W } \\
\text { (m) }\end{array}$ & $\begin{array}{c}\text { UTM-S } \\
\text { (m) }\end{array}$ & Altitude (m) & $\begin{array}{c}\text { N. Potenc. } \\
\text { (m) }\end{array}$ & $Q\left(\mathrm{~m}^{3} / \mathrm{h}\right)$ & $\mathbf{Q} / \mathbf{s p}\left(\mathbf{m}^{3} / \mathbf{h} / \mathbf{m}\right)$ & E.A. (m) \\
\hline 679250 & 7202700 & 995 & 968,19 & 79,13 & 14,65 & $48-50 ; 66-68$ \\
\hline 680950 & 7202700 & 965 & 968,50 & 150 & 7,5 & $70-79$ \\
\hline 681940 & 7202580 & 947 & 942,45 & 208 & 131,64 & $23 ; 34$ \\
\hline 679210 & 7202640 & 998 & 999,50 & 92 & 16,11 & $42,9-44,1$ \\
\hline 679710 & 7202415 & 990 & 965,88 & 150 & 13,18 & 39,$5 ; 59$ \\
\hline
\end{tabular}

Tabela 3 - Relação de fontes/surgências cadastradas e georeferenciadas no Sub-compartimento Colombo.

\begin{tabular}{|c|c|c|}
\hline UTM-W (m) & UTM-S (m) & Altitude (m) \\
\hline 678260 & 7202750 & 1009 \\
\hline 679180 & 7202770 & 990 \\
\hline 679300 & 7202740 & 960 \\
\hline 681230 & 7202430 & 958 \\
\hline 681240 & 7203210 & 940 \\
\hline 681550 & 7202440 & 945 \\
\hline 681990 & 7202610 & 945 \\
\hline 681920 & 7202720 & 955 \\
\hline 681610 & 7203880 & 940 \\
\hline 682200 & 7204250 & 942 \\
\hline 682400 & 7203340 & 938 \\
\hline 682480 & 7203780 & 930 \\
\hline 683540 & 7203720 & 935 \\
\hline 683840 & 7204200 & \\
\hline
\end{tabular}

Tabela 4 - Relação de fontes/surgências cadastradas e georeferenciadas no Sub-compartimento Almirante Tamandaré

\begin{tabular}{|c|c|c|}
\hline UTM-W (m) & UTM-S (m) & Altitude (m) \\
\hline 672520 & 7201460 & 948 \\
\hline 671230 & 7201040 & 950 \\
\hline 671090 & 7198590 & 950 \\
\hline
\end{tabular}

Ainda nesta região, foram cadastradas quatorze fontes/surgências alimentadas pelo aqüífero cárstico (Tabela 3 ).

A determinação da direção de fluxo das águas subterrâneas, neste Sub-compartimento, é bastante problemática. Entre uma unidade morfoestrutural e outra, o fluxo parece se inverter. Isto pode ser devido a decorrência do represamento das águas pelos diques de diabásio. Como este Subcompartimento é aquele que apresenta a maior área de rocha carstificada, as diferenças altimétricas são pouco expressivas (zonas carbonáticas rebaixadas no terreno) e o represamento propiciado pelos diques faz com que ocorra fluxos diferenciados.

Com relação às entradas de água, observou-se que em 11 poços tubulares perfurados nas localidades de Fervida, São João e Capivari, as profundidades delas variam entre 34 e $132 \mathrm{~m}$ de profundidade. A profundidade média dessas zonas produtoras é de $41 \mathrm{~m}$, sendo que em $68 \%$ dos casos os valores são inferiores à média. É de se esperar que o bombeamento dos poços neste Subcompartimento deverá produzir 
Tabela 5 - Relação de alguns poços tubulares cadastrados e georeferenciados no Sub-compartimento Almirante Tamandaré.

\begin{tabular}{|c|c|c|c|c|c|c|}
\hline $\begin{array}{c}\text { UTM-W } \\
(\mathbf{m})\end{array}$ & $\begin{array}{c}\text { UTM-S } \\
(\mathbf{m})\end{array}$ & $\begin{array}{c}\text { Altitude } \\
(\mathbf{m})\end{array}$ & N.Potenc. $(\mathbf{m})$ & $\mathbf{Q}\left(\mathbf{m}^{\mathbf{3}} \mathbf{h} \mathbf{h}\right)$ & $\mathbf{Q} / \mathbf{s p}\left(\mathbf{m}^{\mathbf{3} / \mathbf{h} / \mathbf{m})}\right.$ & $\mathbf{E .}^{\mathbf{a}}(\mathbf{m})$ \\
\hline 671980 & 7200600 & 948 & 942,55 & 49,5 & 4,33 & $57 ; 60$ \\
\hline 673670 & 7199540 & 940 & 936,8 & 180 & 15 & $40 ; 65 ; 90$ \\
\hline 673635 & 7199530 & 938 & 936,8 & 180 & 15 & $51 ; 88 ; 96$ \\
\hline 673660 & 7199350 & 938 & 932,45 & 166,74 & 1,29 & 148 \\
\hline 673630 & 7199330 & 938 & 932,81 & 49,5 & 0,77 & $35 ; 148$ \\
\hline
\end{tabular}

Tabela 6 - Relação de alguns poços tubulares cadastrados e georeferenciados no Sub-compartimento Almirante Tamandaré.

\begin{tabular}{|c|c|c|c|c|c|c|}
\hline $\begin{array}{c}\text { UTM-W } \\
(\mathbf{m})\end{array}$ & $\begin{array}{c}\text { UTM-S } \\
(\mathbf{m})\end{array}$ & $\begin{array}{c}\text { Altitude } \\
(\mathbf{m})\end{array}$ & N.Potenc. $(\mathbf{m})$ & $\mathbf{Q}\left(\mathbf{m}^{\mathbf{3} / \mathbf{h})}\right.$ & $\mathbf{Q} / \mathbf{s p} \mathbf{( \mathbf { m } ^ { 3 } / \mathbf { h } / \mathbf { m } )}$ & $\mathbf{E .}^{\mathbf{a}(\mathbf{m})}$ \\
\hline 671720 & 7198140 & 936 & 932,73 & 184 & 62,59 & $12-18 ; 35$ \\
\hline 671365 & 7198150 & 940 & 937,93 & 172 & 34,89 & 16 \\
\hline 673620 & 7199480 & 938 & 936,05 & 120 & 15,89 & 48,2 \\
\hline 673670 & 7199540 & 938 & 936,15 & 150 & 19,6 & $42 ; 45$ \\
\hline 673650 & 7199465 & 938 & 933,85 & 120 & 88,8 & 45 \\
\hline 672600 & 7200840 & 948 & 943,74 & 52 & 7,22 & $39 ; 66$ \\
\hline
\end{tabular}

rebaixamentos do nível potenciométrico acentuados devido à concentração dos mesmos numa pequena área.

A análise dos resultados dos testes de bombeamento dos poços tubulares revelou que as bacias hidrográficas do rio Tumiri e do rio Capivari apresentam comportamento hidráulico distinto entre si. A partir dos dados calculados pelos referidos autores, a estimativa encontrada em termos de volume armazenado em sub-superfície, corresponde a $6,47 \times 10^{6} \mathrm{~m}^{3} / \mathrm{km}^{2}$ para as áreas das nascentes do rio Capivari e 14,92 x $10^{6} \mathrm{~m}^{3} /$ $\mathrm{km}^{2}$ para a bacia do rio Tumiri. Estes resultados, todavia, devem ser considerados com ressalvas, em função das características anisotrópicas, típicas de aqüíferos cársticos e não devem ser extrapolados para áreas vizinhas por não significarem médias regionais.

A Companhia de Saneamento do Paraná (SANEPAR) opera seis poços tubulares no perímetro urbano de Colombo, cuja vazão total corresponde a $655,20 \mathrm{~m}^{3} / \mathrm{h}$. Este volume atende a região de Colombo até o bairro de Santa Cândida, em Curitiba.

\section{Almirante Tamandaré}

A análise geo-morfoestrutural deste Sub-compartimento permitiu a separação de dez unidades morfoestruturais, em função do posicionamento de dez diques de diabásio e da presença de filitos e de quartzitos. As três fontes/ surgências (Tabela 4) cadastradas neste Sub- compartimento estão situadas em duas unidades morfoestruturais. Os poços tubulares, em número de 19 entre poços produtivos e improdutivos, distribuem-se ao longo de três unidades principais, sendo que dois destes poços estão localizados na mesma unidade de duas fontes/surgências (Tabelas 5 e 6 ).

$\mathrm{Na}$ unidade morfoestrutural, em que está localizada a cidade de Almirante Tamandaré, foram perfurados 12 poços tubulares, aproveitando-se a infraestrutura de distribuição e armazenamento de água existente. Os resultados de explotação obtidos foram significativos, identificando-se uma vazão média de $180 \mathrm{~m}^{3} / \mathrm{h}$ por poço e uma capacidade específica média de $22,65 \mathrm{~m}^{3} / \mathrm{h} / \mathrm{m}$. O sentido do fluxo das águas subterrâneas, nesta unidade, ocorre de norte para sul, em direção à bacia do rio Iguaçu.

Ressalte-se que durante a fase de testes de produção, quando foi bombeado simultaneamente de três poços a uma taxa total de 1.080 $\mathrm{m}^{3} / \mathrm{h}$, ocorreu solapamento do terreno com conseqüentes rachaduras em residências situadas nas proximidades dos poços. A partir de agosto de 1992, até recentemente, a bateria de poços na cidade de Almirante Tamandaré tem operado com quatro poços a uma vazão total de $430 \mathrm{~m}^{3} / \mathrm{h}$. Em função do monitoramento das vazões extraídas e dos respectivos níveis de água (nível dinâmico) de cada poço, não foi detectado problema de ordem geotécnica na intensidade como ocorreu no Subcompartimento Colombo. 
Tabela 7 - Relação de alguns poços tubulares cadastrados e georeferenciados no Sub-compartimento Várzea do Capivari.

\begin{tabular}{|c|c|c|c|c|c|c|}
\hline $\begin{array}{c}\text { UTM-W } \\
\text { (m) }\end{array}$ & $\begin{array}{c}\text { UTM-S } \\
\text { (m) }\end{array}$ & $\begin{array}{c}\text { Altitude } \\
\text { (m) }\end{array}$ & N.Potenc. (m) & $\mathbf{Q}\left(\mathbf{m}^{3} / \mathbf{h}\right)$ & $\mathbf{Q} / \mathbf{s p}\left(\mathbf{m}^{3} / \mathbf{h} / \mathbf{m}\right)$ & E.A. (m) \\
\hline 685545 & 7206035 & 885 & 869,7 & 120 & 28,57 & 39,9 \\
\hline 683570 & 7207200 & 890 & 886,5 & 5,28 & 4 & $12 ; 19$ \\
\hline
\end{tabular}

Tabela 8 - Relação de alguns poços tubulares cadastrados e georeferenciados no Sub-compartimento Cabeceira.

\begin{tabular}{|c|c|c|c|c|c|c|}
\hline $\begin{array}{c}\text { UTM-W } \\
\text { (m) }\end{array}$ & UTM-S (m) & $\begin{array}{c}\text { Altitude } \\
\text { (m) }\end{array}$ & N.Potenc. (m) & $\mathbf{Q}\left(\mathbf{m}^{3} / \mathbf{h}\right)$ & $\mathbf{Q} / \mathbf{s p}\left(\mathbf{m}^{3} / \mathbf{h} / \mathbf{m}\right)$ & E.A. (m) \\
\hline 675625 & 7202465 & 991,6 & 984,29 & 204,2 & 17,5 & 30 \\
\hline 675325 & 7202100 & 990 & 981 & 152,4 & 25,61 & 34 \\
\hline 676070 & 7203420 & 1036 & 1031 & 0 & 0 & 48 \\
\hline 675720 & 7201470 & 975 & 973,1 & 158 & 112,86 & $35 ; 43$ \\
\hline
\end{tabular}

Tabela 9 - Relação de fontes/surgências cadastradas e georeferenciadas no Sub-compartimento Cabeceira.

\begin{tabular}{|c|c|c|}
\hline UTM-W (m) & UTM-S (m) & Altitude (m) \\
\hline 675170 & 7202120 & 982 \\
\hline
\end{tabular}

Várzea do Capivari

O Sub-compartimento Várzea do Capivari apresenta-se seccionado por cinco diques de diabásio, configurando com as rochas metassedimentares 9 unidades morfoestruturais principais. Existem quatro poços tubulares em duas destas unidades, sendo que três poços foram perfurados em uma unidade e o outro numa outra (Tabela 7).

\section{Cabeceira}

Neste Sub-compartimento estão cadastrados cinco poços tubulares, os quais se distribuem em três unidades morfoestruturais distintas (Tabela 8). Com base no traçado de nove diques de diabásio e na posição dos filitos, quartzitos e metadolomitos, individualizou-se onze unidades principais.

A fonte cadastrada (Tabela 9), a qual se situa na parte norte deste Sub-compartimento, encontra-se localizada próxima do poço tubular de Boixininga.

\section{DISCUSSÃO/CONCLUSÃO}

As áreas delimitadas pelos compartimentos denominados Colombo, Almirante Tamandaré, Várzea do Capivari e Cabeceira, apresentam um potencial hidrogeológico viável sob o ponto de vista técnico e econômico e, por esta razão, pode ser aproveitado para o abastecimento da Região Metropolitana de Curitiba (RMC). Nessas áreas devem ser enfocados os futuros estudos de detalhes hidrogeológico para aumentar o volume de água a ser captado no subsolo e assim minimizar o deficit que ocorrerá em função do crescimento acelerado da RMC. Os dados obtidos até o momento mostram, por outro lado, que a água subterrânea armazenada no aqüífero cárstico de Curitiba quando extraída através do bombeamento de poços tubulares, podem influenciar diretamente nas descargas das fontes, bem como causar o acomodamento do terreno nas imediações onde se localizam as captações. Por esta razão, é imprescindível que os futuros poços sejam projetados para locais distantes das áreas ocupadas pela população e das nascentes naturais que originam a rede de drenagem da região. Sob esta ótica, vale salientar que é de suma importância a implantação de ações com base em critérios legais para estabelecer regras para a ocupação populacional, industrial e sobre o uso continuado de agro-químicos na região. Para a escolha das novas áreas de investigação hidrogeológica não deve ser prescindido a possibilidade de aproveitar o excedente hídrico da região, injetando-o no subsolo para aumentar a capacidade de armazenamento e de produção através de unidade ou de baterias de poços tubulares. Tratando-se de uma proposta de procedimento inédito na região, para a escolha do primeiro experimento nesse sentido deve ser baseado a partir de considerações, tais como na qualidade e quantidade da água da fonte de recarga, na distância entre a fonte e o ponto de recarga, na infra-estrutura existente, nos condicionantes ambientais, no uso e ocupação do solo e por último nos aspectos legais, especialmente relativos ao uso do solo. Uma vez estabelecidas estas regras, tornar-se-á possível minimizar o caráter subjetivo na escolha da área piloto, atribuindo-se a cada um destes critérios acima especificados um ponderador fixo de acordo com sua importância relativa nas áreas em questão. 


\section{REFERÊNCIAS}

BIGARELLA, J.J.; SALAMUNI, R. - 1956 - Estudos preliminares na Série Açungui. V Estruturas organógenas nos dolomitos da Formação Capiru (PR). V. 6-7. p. 317-322. Curitiba.

BIGARELLA, J.J.; SALAMUNI, R. - 1958 Contribuição à geologia da Região Sul da Série Açungui (PR). Bol. Paulista de Geog. v. 29. p. 03-19. São Paulo.

CPRM (Companhia de Pesquisas de Recursos Minerais) - 1998 - Curitiba - Folha SG.22-X-D-I Estado do Paraná. Programa levantamentos geológicos básicos do Brasil. São Paulo. DNPM - CPRM - Min. Minas e Energia 79 pág.

FAIRCHILD, T.R. - 1977 - Conophyton of other stromatolites from the upper Pre-Cambrian Açungui Group Near Itapeva, SP, Brasil. $1^{\circ}$ Simp. Reg. Soc. Bras. Geol. São Paulo.

FASSBINDER, E. - 1996. A Unidade Água Clara no contexto do Grupo Açungui: um modelo transpressivo de colisão oblíqua no Neoproterozóico paranaense. São Paulo, IG/USP. 207 p. (Tese de Doutorado).

FIORI, A.P. - 1990 - Tectônica e estratigrafia do
Grupo Açungui a norte de Curitiba. Tese de livre docência. IG/USP - São Paulo. 261p. Ilust.

FIORI, A.P. - 1992 - Tectônica e estratigrafia do Grupo Açungui - PR. Boletim IG-USP, Série Científica, 23:55-74.

FUCK, R.A. MARINI, O.J; TREIN, E; MURATORI, A. - 1971 - Geologia do leste paranaense. An. XXV Cong. Bras. Geol. p. 122-130. São Paulo.

MAACK, R. - 1947 - Breves notícias sobre a geologia dos Estados do Paraná e Santa Catarina. Arq. Bol. Técn. V. 2. p. 63-154. Curitiba.

MARINI, O.J. - 1970 - Geologia da Folha de Rio Branco do Sul - PR. Tese da Fac. Filos. Ciências e Letras, Rio Claro - SP, inédito, 190 p.

SOARES, P.C. - 1987 - Seqüências tectonosedimentares e tectônica deformadora no centro-oeste do Escudo Paranaense. In: Simp. Sul-Bras. Geol. 3. Curitiba. 1987. Atas Curitiba. SBG. v.2, p.743-771.

SUDERHSA - Superintendência de Recursos Hídricos e Saneamento Ambiental. Atlas Hídrico do Estado do Paraná, 1999. 